\title{
THE DEVELOPMENT OF HEART SURGERY IN CHILDREN
}

BY

\section{SIR RUSSELL BROCK*}

I must thank ycu for inviting nie to te one of your guests of honour and to speak to you on the development of heart surgery in children. This is a big task but one of special interest to me because I have been fortunate in having watched much of this development and even participated in some small part.

I start with a story. In 1930 I had the privilege of spending a year in St. Louis with Dr. Evarts Graham as a Rockefeller Research Fellow. Pulmonary surgery was about to unfold and heart surgery was almost non-existent and entirely non-existent in children. Professor Graham, who as you know was a great surgical pioneer, was interested in the possibilities of heart surgery and had begun some work on the surgical relief of mitral stenosis. He told me that in the early 1920's he became convinced that it was desirable and feasible to close the persistent ductus arteriosus. He therefore approached the professor of paediatrics at the St. Louis Children's Hospital, explained his thoughts and plans, and asked if a patient could be sent to him with a view to operation. The paediatric professor without further comment sent along a man aged 53 years.

I have no doubt that he thought this was a clever act, powerful enough to stop once and for all this imaginative but troublesome surgeon. It was, of course, a cruel and stupid thing to do and, as Graham said, delayed the advent of cardiovascular surgery in children for some 15 years until Robert Gross, encouraged and stimulated by a physician wiser than the professor at St. Louis, achieved the first successful closure of a ductus and ushered in the cardiovascular surgery of childhood. This great paediatric surgeon, in addition to making many other contributions, shared also the establishment of the surgery of aortic coarctation.

While I was in St. Louis the leading thoracic surgical problems lay in connexion with lung surgery and especially with lung resection, both in children and in adults. The development of heart surgery was scarcely possible before familiarity with intrathoracic techniques had been established, including that of the parallel disciplines of anaesthesia, blood

\footnotetext{
* President of the Royal College of Surgeons, and guest Lecturer at a meeting of the British Association of Paediatric Surgeons in Rotterdam, September 1964.
}

transfusion, chemotherapy, radiology etc. The path to this achievement was fated to lie in the surgery of the lungs and again I was fortunate to be a ringside observer. In this year while I was in St. Louis, Shenstone and Janes of Toronto announced their success with one-stage lobectomy for bronchiectasis in the development of the tourniquet technique pioneered by Brun of San Francisco. Their report of 11 patients operated on with only 2 deaths was epoch-making because it not only proclaimed the ability to cure the loathsome disease of bronchiectasis but showed the way by which familiarity and success. could be achieved in operating within the thorax. The eight years that remained of the 1930's before the second war came to disrupt normal progress were the golden years of lung surgery and of thoracic surgery and culminated in 1938 in the success of Robert Gross to which I have already referred. I emphasize to you again how, in my opinion, the establishment of safe thoracotomy for non-cardiac intrathoracic disease was the essential preliminary to the advent of cardiac surgery.

Dwight Harken's splendid work during the war on the successful removal of foreign bodies from within the chambers of the heart showed that the heart could tolerate direct intervention, and when the war ended the stage was set for the exciting development of heart surgery that we have since witnessed.

It seems convenient to divide progress into that of closed operations and of open operations for heart disease.

\section{Closed-heart Surgery}

Many of the closed procedures are now of chiefly historical interest because they have been replaced by open technique, but' a place still remains for closed operations. This is often so in infants and small children who do not well tolerate open operations done with present techniques of total body perfusion. It may be that newer techniques will be better tolerated, but at present this intolerance of very young children for open procedures must be recognized.

I need not expand upon the surgery of persistent ductus and of aortic coarctation because most of you are familiar with these two conditions. I merely 
mention the complex and difficult problems that arise when either is associated with other congenital heart lesions; especially congenital mitral stenosis, ventricular septal defect, and aortic stenosis. With such combinations we are faced with grave problems to which I can do no more than refer in this short address.

Of the closed procedures I must mention closed pulmonary valvotomy and closed operations on the outflow tract of the right ventricle.

Closed pulmonary valvotomy for pure valve stenosis or associated with reversed flow through an atrial communication has been largely displaced by open valvotomy; a development that all must welcome. I would not like you to think, however, that there is no place for closed pulmonary valvotomy. It is still an excellent and safe operation in poor risk cases; some of these are in older patients, especially over 20 years of age, who are severely cyanosed; another group consists of very young children or infants and especially those who are deeply cyanosed. A quick closed valvotomy can be not only life saving but can give a brilliant and longlasting result. Many of you may not agree with this and will prefer an open valvotomy on all occasions. I must tell you that I have many patients who remain in excellent health and with complete relief of their pulmonary stenosis, having been operated on as children ten or more years ago. Cyanosis is usually completely relieved even when the atrial communication is not closed. In only a few cases has it proved necessary to close the septal defect by a second operation.

We have, in connexion with pulmonary valvotomy, the problem of coincident secondary infundibular stenosis due to hypertrophic muscular changes. Most of you are familiar with this but some may not be, and I must explain briefly that even after an open valvotomy in which there can be no doubt about the complete relief of the valve stenosis the pressure in the right ventricle may still be as high as before, or even higher. The explanation lies in the fact that as soon as the ventricle is decompressed by the valvotomy the grossly hypertrophied walls of the infundibulum approximate during systole and constitute another obstruction. This obstruction can be relieved by resection of the infundibulum and the right ventricular hypertension may be immediately converted. In case you think the problem is thus easily solved I will show you examples in which this is not so; in fact the hypertension may be made worse. Nature in time can correct this state over the course of one to two years, and with the spontaneous regression of the right ventricular hypertrophy the pressure in the right ventricle returns to normal.
In spite of this observation that a natural cure can occur, it is still dogmatically stated that if hypertension is present after valvotomy, infundibular resection is obligatory. I warn you against accepting this advice and practice without deeper study of the facts. I specially warn you of this in young children who, of course, are your chief concern.

In children the muscular hypertrophy in response to valve obstruction may be florid and excessive and this is especially significant when one considers the absolute smallness of the right ventricular cavity and how it may be much more severely obstructed than in an adult. It is particularly dangerous to do an open infundibular resection on little children in such circumstances, because you will find that it is difficult or impossible to perform a satisfactory resection of the very thick muscle and it may be quite impossible to relieve the right ventricular hypertension. The net result is that in addition to carrying the burden of the unrelieved ventricular hypertension the patient has suffered a major damage to the efficiency of the right ventricle by virtue of the incision and resection. It is small wonder that the mortality is high. There may still be an argument for infundibular resection in older children, but I strongly advise you against doing this in young children and especially when the right ventricular pressure is as high as 200 or $250 \mathrm{~mm}$. $\mathrm{Hg}$. The temptation is then great; so is the risk of failure and the risk of death; and so is the ability of the ventricular hypertrophy to recede spontaneously. Be patient and wait. You are much more likely to have a live patient, and if the right ventricular hypertension does not resolve spontaneously you can always do a secondary operation.

The management of hypertrophic infundibular stenosis illustrates the great difference between simple operating and true surgery; between cutting and thinking. In heart surgery, as in all other branches, it is not enough to be able to do a particular operation. The significance of every procedure must be understood by a full knowledge of the underlying problems presented.

I now come to closed operations on the outflow tract of the right ventricle in Fallot's tetralogy. This grave condition consists essentially of a varying degree of pulmonary stenosis and a ventricular septal defect. The pulmonary stenosis is caused by valvar stenosis or infundibular stenosis or by a combination of the two.

The brilliant contribution of Blalock and Taussig demonstrated that the obstruction to the outflow of blood from the right ventricle could be by-passed by a systemic-pulmonary anastomosis; the Potts' operation follows the same principle. These 
operations have been and still are widely accepted, and rightly so. I notice, however, that among the published papers of this meeting is an article on the surgical palliative treatment of the tetralogy of Fallot in children, in which it is rightly pointed out that complete correction, using extracorporeal circulation, is often not possible in children, and it mentions the need for some preliminary procedure or first stage operation. It is stated, 'the only surgical treatment in this group of children is to improve the pulmonary flow by means of a Blalock or Potts anastomosis'.

I must point out, with some sorrow, that this statement is just not true. Excellent palliation is possible by relief of the outflow tract obstruction either by valvotomy or by infundibular resection or by both combined. This is in accord with sound surgical principles and achieves more than a shortcircuiting procedure, which a systemic-pulmonary anastomosis essentially is. Increasing the blood flow through the right ventricular outflow tract encourages the growth and development of the tract so that the haemodynamic conditions are more favourable when the time comes to close the septal defect. I cannot enlarge upon this subject here but must refer you to my many writings on it and also to the supporting writings of others. By all means reject palliative operations on the outflow tract or say you do not like them, but please do not ignore them. This indicates either ignorance of their existence or contempt for them. They can be very useful in infants or young children who are gravely ill and deeply cyanosed. A quick closed operation on the outflow tract can give results as good as an anastomotic procedure and often with less disturbance. You should follow the example of many cardiac and paediatric surgeons and try them.

\section{Open-heart Surgery}

I now come to the vast field of open-heart surgery and can only deal with it in rather general terms aided by references to a few specific problems.

We all recognize the very high mortality in newborn babies and infants during the first 6-12 months of life from congenital heart lesions. Many of these are incurable, but even when an anatomically curable condition is present the infant will usually not tolerate a radical operation. Hence, whenever feasible, the preference is for some palliative procedure that will carry the infant on until he can tolerate a fully corrective operation. One of the most difficult problems is that of transposition of the great vessels and my friend Dr. Brom will deal with this in a separate lecture.

At present these young patients do not tolerate total body perfusion well. A special heart-lung machine is essential for them, but even then the margins of haemodynamic inbalance are easily transgressed and this is badly tolerated. This does not mean, however, that we must admit defeat. It remains a challenge to surgery, and sooner or later the grave problems of open-heart surgery in babies and small infants will be largely overcome.

The reluctance to operate on very small infants is obligatory, but it is often quite wrong to show the same reluctance in older children. A decision not to operate or to delay operation often springs from prejudice or fear, or from ignorance of the factors involved. The heart of a child of 5 years or more with an atrial septal defect and even more so with a ventricular septal defect is exposed to unnecessary and undesirable overwork all day and every day, exactly as with a persistent ductus, and closure is indicated to relieve the cardiovascular burden alone. But there is another strong reason for correcting the abnormality; one that I am sure that an audience of paediatric surgeons is acquainted with as it plays an important part in many other diseases, namely general retardation of growth and the development of severe thoracic skeletal deformities. I notice a paper is in fact being presented at this congress on the physical development of children with congenital heart disease, and I need only emphasize this important consideration and how the years that the locusts have eaten can never be regained, as the skeletal deformity or retardation of growth cannot be fully corrected.

A straightforward atrial septal defect of secundum type should present no problem in a child. Various techniques can be used to expose the lesion; conventional hypothermia, total body perfusion with a standard pump oxygenator or the disposable oxygenator primed with $5 \%$ dextrose as popularized particularly by Denton Cooley. This latter technique has certain advantages for a short procedure in children, including easing the demand on the supply of blood, now so important with open-heart surgery. Much more caution is necessary in an atrial septal defect of primum type; the technical difficulties in these can be very great and the mortality and morbidity can be high. It is often wiser to delay operation in children.

Uncomplicated ventricular septal defect is also a relatively straightforward procedure and my policy is to recommend routine closure even when the lesion is a small one, though usually not before the age of 5 to 7 years.

When the defect is large or when it is complicated by a rise in pulmonary arterial resistance, the risk and problems of operation increase. I can only 
refer to the problems of heart block; the best treatment is avoidance, and the technique of closure must be directed to this. If heart block occurs, it must always be controlled either temporarily or permanently by a pacemaker. It is no good hoping for the best and doing nothing or relying upon medical means.

The problems of raised pulmonary artery resistance are also difficult and complex. We know that this is often present in infants, and operation below the age of 2 years is followed by a very high mortality. Temporizing is necessary; perhaps in newborn babies with a palliative procedure, such as banding the pulmonary artery. I am convinced that the changes in the lung vessels in children are not permanent and certainly are not progressive. I have observed regression over the years and feel that it is wrong to operate on an infant simply because of fear that the pulmonary resistance will worsen or will become permanently raised. Many infants and young children have lost their lives because of too early operation.

Congenital mitral stenosis and regurgitation are serious lesions. My experience with the former has been particularly disappointing and even with an open operation it is difficult or impossible to correct the severely mal-developed valve.

The present results of operation for congenital aortic valve stenosis are good and the mortality is low. In the early days, especially when hurried operations were done under hypothermia, serious regurgitation was often inflicted. Experience has shown the need for great care in cutting the valve, and that serious complication is now less common. I feel, however, that the long-term results of aortic valvotomy for congenital stenosis in children will be disappointing and certainly so with a bicuspid valve. Calcification and recurrence of stenosis seem inevitable and the same must occur when the valve cusps contain large myxomatous nodules. In many such cases valve excision and replacement will be needed later in life, and a guarded prognosis must be given.

I have already made a brief reference to Fallot's tetralogy and the place for palliative operations. I now turn to its radical cure or so-called total correction.

The most difficult common congenital heart lesion we have to deal with is transposition of the great vessels, and the second most difficult is Fallot's tetralogy. I emphasize that Fallot's tetralogy is always a serious lesion; even when the clinical state is not severe the actual cardiac lesion is always severe. All treatment and management must be based on this fact.

I am against performing a total corrective opera- tion in young children below the age of 7 years. I am aware that success is possible in younger children but the mortality is so much higher that it is not wise to expose the child to the extra risk. The younger the child the more does this apply. Total correction of Fallot's tetralogy is a severe physical strain for a child to undergo and many are just not strong enough nor have sufficient reserve to tolerate it. A preliminary operation such as an anastomosis or an outflow tract operation is desirable to carry the child along until he is older and stronger.

I have great reservations about the use of an outflow patch and particularly one that extends across the pulmonary valve into the pulmonary trunk, thus causing severe pulmonary regurgitation. It is disturbing, even distressing, to read reports of outflow patches being used in some two-thirds of patients submitted to 'total correction'. This is not total correction because the heart is still far from normal. If the outflow tract is too small to carry the correct amount of blood, it is better to give Nature a chance to enlarge it by doing a preliminary relief of outflow tract obstruction rather than rushing things by artificially enlarging the outflow by sewing in a gusset. The years ahead are likely to disclose disappointments after this so-called total correction.

\section{Conclusions}

I have barely touched on the problems of heart surgery in children, but I wish to refer to some of the problems of organization which have appeared now that success has been achieved and now that paediatric surgery has come so much into its own as a specialty.

Everyone must surely accept that the problems of operating on and caring for newly born and young infants demand the organization, resources, and skills of special paediatric units. I need not, before this audience, enlarge upon the requirements of special knowledge, of nursing skills, and of special equipment and ward design and organization. The surgeon who wishes to undertake these difficult and anxious cardiac operations in very young patients must either be a paediatric surgeon who has chosen cardiovascular surgery as an extra specialty within his specialty or a cardiac surgeon who elects to make a special study of these infant problems and works closely with a paediatric colleague in a properly organized unit or hospital. Without this I can see little prospect of good work being achieved.

In older children this need is not so urgent. Older children of course derive great benefit from being in a special paediatric environment, but the operating and after-care do not demand the same highly specialized paediatric knowledge and experience as in the case of 
young infants. The essential requisite is experience and ability in cardiac surgical techniques. If these are possessed by a paediatric surgeon then a very happy position exists. I think you will agree that there is no justification for a paediatric surgeon, just because he is a paediatric surgeon, to attempt these very difficult cardiac procedures in children. The road to specialization lies with the necessary techniques and special clinical knowledge and not in the age of the patient.

Advance in this very difficult field of surgery has come and will continue to come both from nonpaediatric surgeons and from paediatric surgeons. I have, for example, mentioned the great contributions of Robert Gross. We all look forward with eager- ness to progress in the field of newborns and infants. Here lie the true problems, the very great difficulties and the present high death rate. But in this field brilliant advances can emerge to save the lives of many more babies suffering from congenital heart disease. Success can only come from close cooperation between paediatrics and cardiac surgery, whether the surgeon be primarily paediatric or cardiac in training.

The problems presented are immense but the joys of success are equally great. Let us hope that it will not be long before a meeting of your Association listens to papers being presented that record the success in cardiac surgery in young infants that we all realize is so desirable. 